\title{
Verify Between the Provided by Forecast Models Acoustical Data and Those Experimental Detected at Messina
}

\author{
Giuseppe Cannistraro $^{1 *}$, Mauro Cannistraro ${ }^{2}$ Cecilia Guglielmino $^{1}$ \\ ${ }^{1}$ Department of Engineering - University of Messina, Messina 98166, Italy \\ ${ }^{2}$ Department of Architecture - University of Ferrara, Ferrara 44121, Italy
}

Corresponding Author Email: gcannistraro@unime.it

https://doi.org/10.18280/ti-ijes.632-415

Received: 2 March 2019

Accepted: 1 May 2019

\section{Keywords:}

noise pollution, environmental noise control, acoustic forecast modelling, noise climate

\begin{abstract}
Noise pollution is by now worldwide recognized as a major problem for the quality of life in urban areas. Noise effects include various impacts on mental and physical health and disturbance of daily activities (may affect sleep, conversation, lead to perception of annoyance, cause hearing loss, cardiovascular problems as well as affect task performance) [1-3].Then, assessing the problem and programming actions for controlling its adverse effects have become issues of immediate concern for community as evidenced by the large number of anti-noise laws, ordinances and regulations decreed by many governments [46]. Also, the EU legislation on environmental noise [7] requires the drawing up of noise maps around main transport infrastructure and in major agglomerations to provide estimates of noise exposure and, where necessary, to work out noise abatement action plans. This paper presents the results of a comparison between the data collected in a previous study of the authors on the environmental noise pollution of the city of Messina (Italy), with the simulated data through the most tested forecasting models in the scientific world. They have been verified the data both by simulation from the models and those obtained experimentally in the same points, after the construction of the works carried out in the city of Messina, consisting of the construction of a motorway junction and a new maritime landing in the southern part of the City. The interventions carried out have significantly modified the vehicular traffic of the urban center, and to verify the effects, comparisons were made with the values measured in the same 35 sites previously surveyed. The comparison was made using simulated values and experimental measurements of the main noise pollution indices (Leq, L1, L10, L50, L90, L99) and of the traffic flow and composition.
\end{abstract}

\section{INTRODUCTION}

Noise is a disturbance signal with respect to information transmitted in a system. It is an oscillatory phenomenon, consisting of sound pressure waves, which allows the transmission of energy through a medium.

This energy generates an unpleasant sensation in the listener affected by the phenomenon.

Although the concept of "noise" as "not pleasant sound" is familiar, it is not so obvious the boundary between what is generically "noise" and what becomes "noise pollution", and as such must be measured, quantified and reduced.

The framework law of 26 October 1995, n. 447 on the subject establishes that noise pollution is the introduction of noise into the external environment or housing such as to cause:

(1) annoyance or disturbance to rest and human activities,

(2) danger to human health,

(3) deterioration of ecosystems, material assets, monuments, the living environment or the external environment or such as to interfere with the legitimate use of the environments themselves.

The effects on humans due to prolonged exposure to environmental noise rarely cause damage directly to hearing (hypoacusis), as in most cases they do not have levels such as to cause damage to the ear.

However, psychosocial-type ones are not negligible, mainly affecting the transmission and under standing of the word, work performance and sleep, and psychosomatics, found on the digestive, respiratory, visual, reproductive, cutaneous and circulatory and blood systems.

Today, noise pollution is the subject of great attention by many scientific groups.

Studies on this topic have been conducted in many cities around the world.

It is recognized all over the world that the quality of life in urban areas is strongly influenced by noise pollution.

Unlike other environmental problems, environmental noise is the growing and it is clear that and exposed persons ask solutions to avoid the growing trend and all the negative effects.

The negative effects of noise on everyday activities, such as sleep and perception of the word, annoyance and on physical and mental health have been documented, as well as having other important consequences, such as economic, cultural and social effects.

Then, assessing the problem and programming actions for controlling its adverse effects have become issues of immediate concern for community as evidenced by the large 
number of anti-noise laws, ordinances and regulations decreed by many governments [4-6].

Also, the EU legislation on environmental noise [7] requires the drawing up of noise maps around main transport infrastructure and in major agglomerations to provide estimates of noise exposure and, where necessary, to work out noise abatement action plans.

In Italy, the acoustic characterization of the territory has received an increasing attention in the last years, in particular since 1991 with the issuing of specific decrees concerning the basic principles and actions aimed at protecting environment against noise pollution [8-11]

In these laws particular emphasis has been addressed to the "acoustic zoning" that has been introduced as the basic technical instrument for the assessment and management of environmental noise.

The acoustic classification, however, is generally made on those urban realities whose development has hardly ever comprised the evaluation of the acoustic aspects and environmental noise. The most common situation is the one in which settlements, initially designed for other uses and characterized by a different noise sensitivity, are placed in close contiguity.

Assess the problem and schedule actions to control adverse effects have become issues of immediate concern of many governments.

In this regard, these governments have issued laws, ordinances and anti-noise regulations that provide for the development of noise maps around the main transport infrastructures and in the main agglomerations to provide estimates of exposure to noise and, where necessary, to draw up action plans for noise reduction.

In Italy, the acoustic characterization of the territory has received an increasing attention in the last years, in particular since 1991 with the issuing of specific decrees concerning the basic principles and actions aimed at protecting environment against noise pollution [8-11].

In these laws particular emphasis has been addressed to the "acoustic zoning" that has been introduced as the basic technical instrument for the assessment and management of environmental noise.

The acoustic classification, however, is generally made on those urban realities whose development has hardly ever comprised the evaluation of the acoustic aspects and environmental noise.

\section{THE RESULTS OF THE CASE STUDY OF THE CITY OF MESSINA}

Messina is a medium-sized ancient town of Sicily (Italy), with about 300 thousand inhabitants.

The city entirely rebuilt after the earthquake of 1908 , it develops longitudinally in the north-south direction along a strip of land $15 \mathrm{~km}$ long, bounded by the mountains and the sea.

The urban centre, where most of the commercial activities and public utilities are located, is characterized by a squaremeshed road network with low buildings and narrow roads. It comprises the structures of the port and of the railway station which provide for the sea-links to and from the continent as shown in Figure 1(a).



Figure 1. Map of Messina city with measurements points

The suburban areas present a typically residential and/or craft character.

The daily contribution of vehicles in transit to and from the continent is estimated in about 8000 motor vehicles and 4000 heavy trucks.

Vehicular flow is principally composed by two streams criss-crossing in the urban centre: one (of resident vehicles) which develops parallel to the coast in the north-south direction and one (mainly of heavy trucks in transit) which develops along orthogonal directions from the highway to the shipping ports.

The lack of alternative ways for these two streams entails the urban centre to be exposed to an intense vehicular traffic with frequent traffic jams and consequent high levels of noise pollution.

In recent years the urban scenario has undergone important structural changes due to the incessant growth in the number of motor vehicles, the expansion of the road network, industrialization, urbanization and the creation of infrastructure (tram-line).

Since the position of the shipping doors has not been changed, these changes have probably led to an increase in noise levels with negative effects on exposed citizens.

The main objective of the survey has been to evaluate the environmental noise in the urban area of the city of Messina, within which there is a road network that connects the port or the two highways PA-ME and CT-ME, to enable a preliminary assessment of noise exposure.

As a first step, the study involved an acoustic classification of the territory in six acoustically homogeneous areas as established by Italian legislation.

Within the city, 35 sampling sites, shown in Table 1, were selected to adequately represent each area resulting from the acoustic zoning for an experimental measurement campaign. A comparison was then made between the measured noise levels and the allowed limits established by the Italian acoustic standards. Based on the municipal acoustic zoning of the city of Messina, divided into six acoustically homogeneous areas (acoustic classes) as shown in Table 2 Noise exposure limits by Italian legislation.

In a survey conducted in the city of Messina [14] in the working days of months of March to May 2003.

Thirty-five sampling points were selected along the streets of the urban center to adequately represent all six acoustically homogeneous areas of the territory deriving from acoustic zoning. 
Table 1. Measurement stations

\begin{tabular}{cccc}
\hline $\begin{array}{c}\text { N } \\
\text { Station }\end{array}$ & Station & $\begin{array}{c}\text { n. } \\
\text { Station }\end{array}$ & Station \\
\hline 1 & Piazza Repubblica & 19 & Via Industriale \\
2 & Via La Farina & 20 & Via G. Natoli \\
3 & Via Taormina & 21 & Via U. Bassi \\
4 & Pizza Castronovo & 22 & Via G. Bruno \\
5 & Piazza Unita d' Italia & 23 & Via Dei Mille \\
6 & Via Garibaldi & 24 & Via Risorgimento \\
7 & Piazza Cairoli & 25 & Via Centonze \\
8 & Via S. Cecilia & 26 & Via Ghibellina \\
9 & Via 1 Settembre & 27 & Via Palermo \\
10 & Via S. Martino & 28 & Viale Giostra \\
11 & Piazza Palazzotoo & 29 & Via C. Battisti \\
12 & Via T. Cannizzaro & 30 & Viale R. Margherita \\
13 & Viale della Liberta & 31 & Via XXIV Maggio \\
14 & Corso Cavour & 32 & Via Taormina bis \\
15 & 15 Viale Boccetta & 33 & Via Dante \\
16 & Viale Europa & 34 & Via Monza \\
17 & Via Consolare Valeria & 35 & Stazione Marittima \\
18 & Piazza del Popolo & & \\
\hline
\end{tabular}

Table 2. Noise exposure limits

\begin{tabular}{|c|c|c|c|}
\hline & Type of Area & $\begin{array}{c}\text { Permissible limit for the Sound level -eq } d(B)(A) \\
\text { Day }(06.00-22.00)\end{array}$ & Equivalent continuous Night (22.00-06.00) \\
\hline $\mathrm{I}$ & Particularly protected areas & 50 & 40 \\
\hline II & Residential areas & 55 & 45 \\
\hline III & Mixed areas & 60 & 50 \\
\hline IV & Areas of intense human activity & 65 & 55 \\
\hline $\mathrm{V}$ & Prevalently Industrial areas & 70 & 50 \\
\hline VI & Exclusively Industrial areas & 70 & 70 \\
\hline
\end{tabular}

Table 3. Experimental data detected in the acoustic survey [14]

\begin{tabular}{|c|c|c|c|c|c|c|c|c|c|c|c|c|}
\hline Site & $\underline{\mathrm{Q}_{\text {(veh/h) }}}$ & 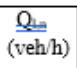 & $\frac{\mathrm{Q}_{\mathrm{wd}}}{(\mathrm{veh} / \mathrm{h})}$ & $\frac{\mathrm{Q}_{\mathrm{nd}}}{(\mathrm{veh} / \mathrm{h})}$ & $\begin{array}{l}\mathrm{L}_{\mathrm{dad}} \\
\mathrm{dB}(\mathrm{A})\end{array}$ & 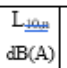 & $\begin{array}{l}\underline{L_{\text {sod }}} \\
d B(A)\end{array}$ & \begin{tabular}{l|}
$L_{\underline{\underline{s i n}}}$ \\
$d B(A)$
\end{tabular} & $\begin{array}{l}L_{\text {sod }} \\
d B(A)\end{array}$ & \begin{tabular}{l|}
$L_{\underline{s_{H}}}$ \\
$d B(A)$
\end{tabular} & \begin{tabular}{l|}
$\underline{\mathrm{L}}$ \\
$\mathrm{dB}(\mathrm{A})$
\end{tabular} & $\begin{array}{c}\mathrm{L}_{a} \\
\mathrm{~dB}(\mathrm{~A})\end{array}$ \\
\hline 1 & 1200 & & 288 & & 75,8 & & 69,3 & & 63,8 & & 72,2 & \\
\hline 2 & 2092 & 349 & 175 & 182 & 77,5 & 74,8 & 70,5 & 66,3 & 64,8 & 57,1 & 74,5 & 72,0 \\
\hline 3 & 2310 & & 220 & & 77,0 & & 71,9 & & 66,9 & & 74,1 & \\
\hline 4 & 2014 & & 76 & & 74,7 & & 67,0 & & 62,0 & & 70,9 & \\
\hline 5 & 2573 & & 126 & & 76,6 & & 70,2 & & 64,7 & & 73,4 & \\
\hline 6 & 3867 & & 207 & & 77,4 & & 71,0 & & 65,7 & & 73,1 & \\
\hline 7 & 1274 & 336 & 57 & 7 & 75,1 & 63,5 & 68,9 & 59,1 & 64,4 & 55 & 74,1 & 61,6 \\
\hline 8 & 1763 & & 84 & & 78,4 & & 70,7 & & 64,3 & & 73,9 & \\
\hline 9 & 677 & & 40 & & 75,9 & & 69,5 & & 64,1 & & 73,2 & \\
\hline 10 & 1905 & & 93 & & 75,5 & & 68,9 & & 63,6 & & 73,6 & \\
\hline 11 & 1412 & & 175 & & 74,6 & & 68,8 & & 63,5 & & 72 & \\
\hline 12 & 966 & & 153 & & 70,2 & & 64,6 & & 60,7 & & 67,6 & \\
\hline 13 & 3093 & 342 & 248 & 103 & 75,1 & 63,6 & 68,0 & 59,2 & 61,4 & 56,6 & 73,2 & 66,7 \\
\hline 14 & 1758 & & 181 & & 76,5 & & 71,1 & & 65,0 & & 73,6 & \\
\hline 15 & 2310 & & 179 & & 77,0 & & 72,0 & & 67,0 & & 72,0 & \\
\hline 16 & 3146 & 453 & 160 & 111 & 76,9 & 73,5 & 70,3 & 61,5 & 64,8 & 57,8 & 74,0 & 71,7 \\
\hline 17 & 1544 & & 134 & & 76,6 & & 70,2 & & 65,6 & & 73,2 & \\
\hline 18 & 1550 & & 34 & & 74,0 & & 66,7 & & 62,4 & & 73,6 & \\
\hline 19 & 323 & & 11 & & 73,7 & & 68,0 & & 62,8 & & 74,1 & \\
\hline 20 & 987 & & 14 & & 70,2 & & 64,5 & & 60,7 & & 67,6 & \\
\hline 21 & 399 & & 24 & & 71,4 & & 64,1 & & 59,3 & & 68,0 & \\
\hline 22 & 1183 & & 37 & & 72,4 & & 66,4 & & 60,3 & & 69,6 & \\
\hline 23 & 628 & & 22 & & 72,8 & & 65,9 & & 62,8 & & 71,2 & \\
\hline 24 & 1078 & & 22 & & 70,4 & & 65,2 & & 59,4 & & 68,0 & \\
\hline 25 & 410 & & 10 & & 71,6 & & 64,7 & & 59,4 & & 68,8 & \\
\hline 27 & 410 & & 13 & & 74,6 & & 68,5 & & 63,5 & & 71,1 & \\
\hline 27 & 1127 & I & 45 & & 73,4 & & 67,2 & & 63,9 & & 70,1 & \\
\hline 28 & 2027 & & 99 & & 73,1 & & 65,2 & & 60,7 & & 71,8 & \\
\hline 29 & 1035 & & 73 & & 72,3 & & 67,3 & & 61,1 & & 69,8 & \\
\hline 30 & 2310 & & 179 & & 77,0 & & 71,9 & & 66,9 & & 74,1 & \\
\hline 31 & 829 & & 52 & & 70,1 & & 64,4 & & 59,9 & & 67,3 & \\
\hline 32 & 2083 & & 298 & & 77,3 & & 71,9 & & 66,7 & & 75,6 & \\
\hline 33 & 1574 & & 119 & & 73,7 & & 67,3 & & 62,5 & & 71,9 & \\
\hline 34 & 1540 & & 79 & & 70,3 & & 65,8 & & 60,8 & & 68,2 & \\
\hline 35 & 148 & 27 & 109 & 87 & 74,9 & 73,4 & 67,8 & 59,9 & 63,5 & 62,5 & 72,5 & 66,5 \\
\hline
\end{tabular}


The measurements were performed following the ISO 1996 guidelines [12-13] which are substantially cited in Italian legislation.

The acoustic survey was carried out on working days and the months of March to May 2003.

Measurements were performed at all sites during the daytime period between 06:00 and 08:00; while measurements for the nocturnal period between $10.00 \mathrm{pm}$ and 6.00 hours, were performed only on six sites. at intervals of $1 \mathrm{~h}$.

In each position and for each interval the time of 15 minutes, it was detected the equivalent continuous sound level weighted A, $\mathrm{L}_{\mathrm{eq}}$, and measured statistical levels $\mathrm{L}_{1}, \mathrm{~L}_{10}, \mathrm{~L}_{50}, \mathrm{~L}_{90}$ and $\mathrm{L}_{99}$, relative at the flows of traffic.

The results have been grouped into two vehicle categories, $\mathrm{Q}_{\mathrm{L}}=$ light vehicles and $\mathrm{Q}_{\mathrm{H}}=$ heavy vehicles.

The data of the measurement campaign performed in the 35 measurement stations is shown in Table 3 , for each vehicle class the daily average values of $\mathrm{Q}_{\mathrm{L}}$ and $\mathrm{Q}_{\mathrm{H}}$ of the traffic composition within each day time interval are shown. and at night, the volume of traffic, expressed in vehicles per hour (veh./h) and the characteristic acoustic parameters: $\mathrm{L}_{1}, \mathrm{~L}_{10}, \mathrm{~L}_{50}$, $\mathrm{L}_{90}$ and $\mathrm{L}_{99}$, expressed in $\mathrm{dB}(\mathrm{A})$.

\section{THE ACOUSTICAL FORECAST MODELS}

A tool of great help for the predicted of the noise is provided by the so - called "previsional models", that allow to help the technician in a work of "modelling" the acoustic situation [14, 27].

Before we can proceed to interpret the data provided by the models, it is advisable to verify its reliability by comparing it with the theoretical forecast data that of some models provide us.

The models use the regression equations obtained are of similar structure and are differentiated by the number of parameters considered and by the conditions of applicability.

The variables that normally appear in the provisional formulas are: vehicle flow, traffic composition, average speed, the main parameters that characterize road traffic, the geometric characteristics of the road, the type of section, the driving habits of users.

Among the forecast models, used to verify their reliability with the experimental data collected in the city of Messina, the most significant models proposed in the literature concerning environmental acoustics were selected and here below presented:

The Burgess model [15] takes into account parameters that characterize vehicular traffic, the time flow of vehicles $Q$ vehicles/hour, the percentage $\mathrm{P}$ of heavy vehicles, as well as the distance $\mathrm{D}$ of noise sources

$\mathrm{L}_{\mathrm{eq}}=55,5+10,2 \log \mathrm{Q}+0,3 \mathrm{p}-19,3 \log \mathrm{d} \quad \mathrm{dB}(\mathrm{A})$

The Griffiths and Langdon model [17] valid for mediumhigh traffic situations (500/5000 veh./hr) expressed by the following expression:

$\mathrm{L}_{\mathrm{eq}}=45.194+10.762 \log \mathrm{Q}-9.64 \log \mathrm{d}+0.122 \mathrm{p} \mathrm{dB}(\mathrm{A})$

M. Cosa and N. Nicoli [16], it bases on average values of ni respectively represent the flows of the vehicles in the time of: cars, light trucks, heavy industrial vehicles, motorcycles and mopeds:
$\mathrm{L}_{\mathrm{eq}}=10 \log \left(4,467 \mathrm{n}_{1}+10 \mathrm{n}_{2}+39,811 \mathrm{n}_{3}+28,184 \mathrm{n}_{4}+7,079 \mathrm{n}_{5}\right)$

$$
+34,437 \quad \mathrm{~dB}(\mathrm{~A})
$$

The model Garcia and Bernal [18] is shown in following Eq. (4). This model considers the following factors: Traffic volume $(\mathrm{Q})$, Percentage of heavy vehicles $(\mathrm{P})$, average flow speed $(\mathrm{V})$, and the width of the roadway $(2 \mathrm{~d})$ :

$\mathrm{L}_{\mathrm{eq}}=55,7+11,2 \log \mathrm{Q}-12,7 \log 2 \mathrm{~d}+0,4 \mathrm{p}-0,05 \mathrm{~V}$

The Calculation of Road Traffic Noise (CoRTN) Model [20], takes into account the following factors: traffic volume, speed, roadway width, and percentage of heavy vehicles:

$\begin{aligned} \operatorname{Leq} & =10 \log Q+33 \log (v+40+500 / v)+10 \log (1+5 p / v) \\ & +0,3 G-27,6 \quad d B(A)\end{aligned}$

The Model Amman, developing by Bassam Salameh and Rana Imam [19], using the measurable parameters that affect the traffic noise level, they have proposed the model: "Roadway Traffic Noise Prediction Models for the City of Amman", that can be expressed by:

$\mathrm{L}_{\mathrm{eq}}=16,7+14,3 \log \mathrm{Q}+23,5 \mathrm{P}+0,676 \mathrm{~T} \mathrm{~dB}(\mathrm{~A})$

The Piccolo et Al model [14], proposes a simple expression for the calculation of $\mathrm{L}_{\mathrm{eq}}$, based on the number of vehicles/hours measured for each time band, grouped in the two types of traffic: $\mathrm{Q}_{\mathrm{L}}$ light vehicles and $\mathrm{Q}_{\mathrm{H}}$ heavy vehicles, using the following eq. (7.1):

$\mathrm{L}_{\mathrm{eq}}=49,56+6,7 \log \left(\mathrm{Q}_{\mathrm{L}}+7,9 \mathrm{Q}_{\mathrm{H}}\right) \mathrm{dB}(\mathrm{A})$

\section{ANALYSIS OF THE RESULTS}

Figure 3 shows the comparison between the data obtained with the 7 simulation models above reported and the values measured experimentally at the site of Station 2 (Via La Farina) in the 11 time slots between 8.00-8.15 and 18.00-18.15.

As can be seen, the models provide values within $5 \mathrm{~dB}(\mathrm{~A})$, respect at experimental values of detected in the station.

The most reliable simulated data are supplied by the Burgess models (Mod.1) and CoRTN (Mod.6) with values that less than $0.5 \mathrm{~dB}(\mathrm{~A})$ respect the experimental values detected at the site.

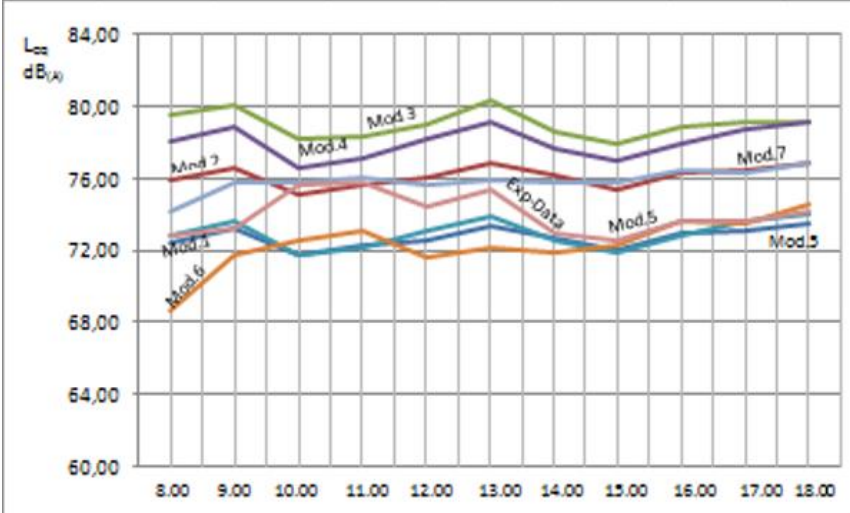

Figure 3. Comparison between the values provided of the 7 models and the experimental data (Daily period) 
In the Figure 4 are shows, respectively the Error percent, of the mean values of the acoustic parameter $L_{e q}$, calculated with the 7 models, respect at the values measured, for the day period for each detection station.

As can be seen in both Figure 4 for the daily period, the average errors committed by almost all models are between 5 and $10 \%$, with the exception of Mod. 6 which presents average errors of more than $10 \%$.

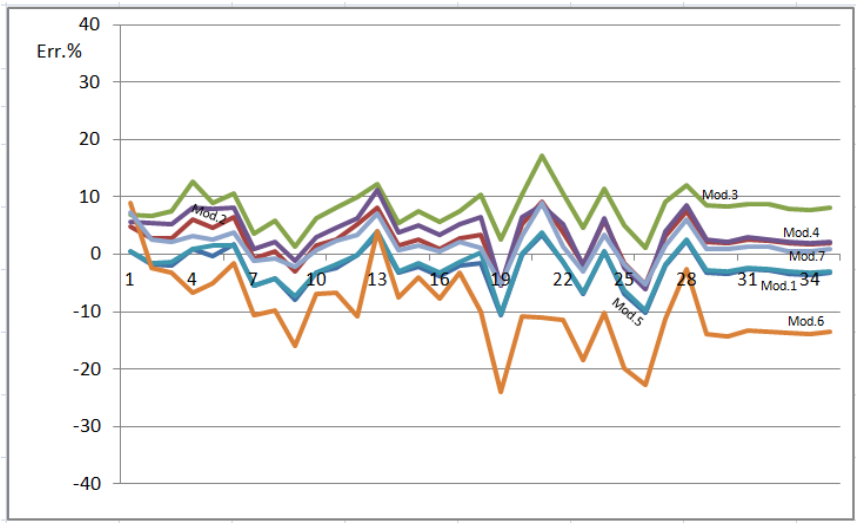

Figure 4. Error percent between the mean values supplied by the 7 models and experimental data (daily period)

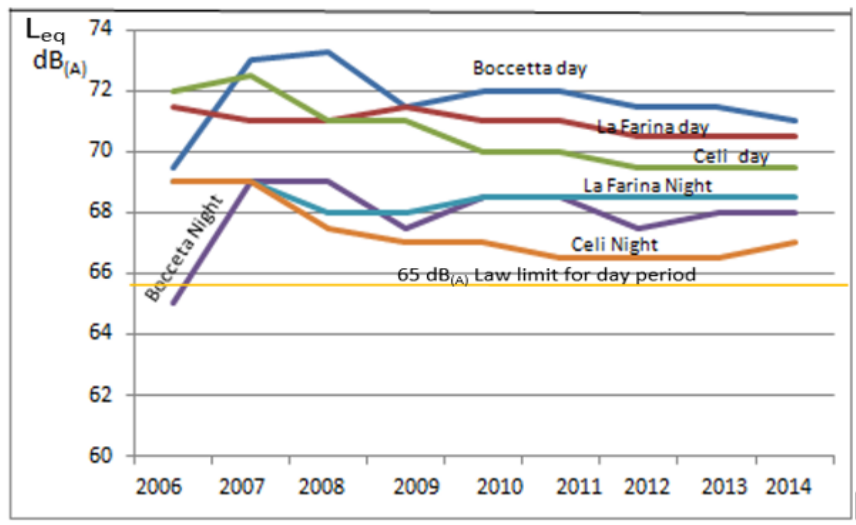

Figure 5. Values of the acoustic parameter, $\mathrm{L}_{\mathrm{eqm}}$, in the day and night period (second survey 2006-14)

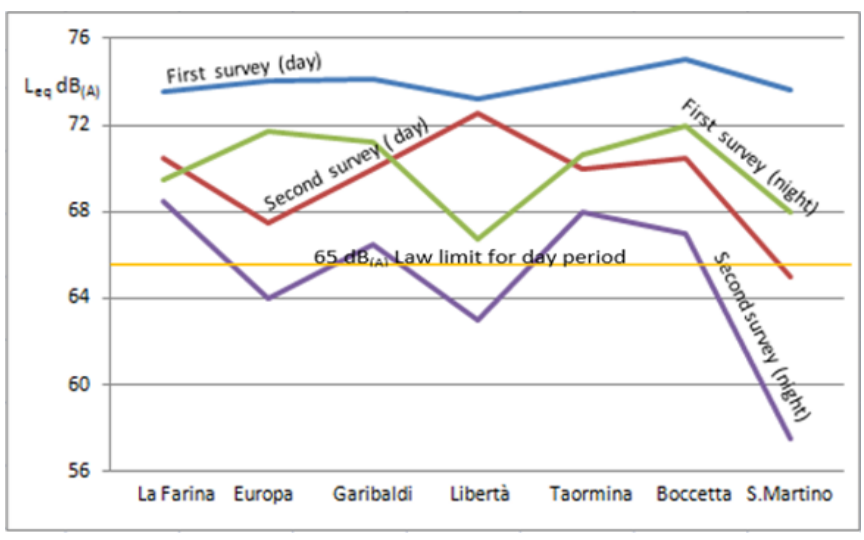

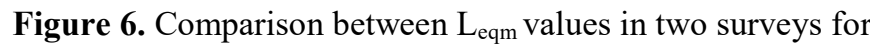
period daily and night in the 7 stations

The values of the acoustic parameters detected experimentally in the first experimental survey have been compared with the corresponding values measured by the Municipality of Messina in the years 2009-2014, in the same stations, after the realization of the works carried out in the city.

As can be seen in the Figure 5 and Figure 6, respectively in the years 2009-14 and 2006-14, both in the daytime and at night, the values of the law are exceeded in all 3 stations.

\section{CONCLUSIONS}

The urban noise survey presented in this study has revealed that even in a medium size city such as Messina, environmental noise levels due to road traffic are notably higher than the limits set by Italian noise standards and policy to protect public health.

In the overall monitoring sites noise daily average sound levels $\mathrm{L}_{\mathrm{d}}$ resulted higher than $67 \mathrm{~dB}(\mathrm{~A})$ and clearly correlated with traffic flow conditions which are nearly saturated in most of the urban roads.

In over $70 \%$ of the examined sampling locations citizens are exposed to $L_{\text {den }}$ levels greater than $73 \mathrm{~dB}(\mathrm{~A})$, causing a relatively high percentage of residents feeling "highly annoyed".

As can be seen in Figure 5 and in Figure 6 in all the measuring points, both the values of the first and of the second survey provide values of the reference acoustic parameter Leq in $\mathrm{dB}(\mathrm{A})$, always above the limit value of law, for both day and night periods of 65 and $55 \mathrm{~dB}(\mathrm{~A})$ respectively.

From the comparison shown in Figure 6, it is also observed that the urbanistic interventions carried out by the Municipal Administration of Messina have involved a significant reduction in noise levels, but not sufficient to be within the law values.

Obviously, the identification of the worst affected areas requires the employment of noise mapping that, cause the relatively small number of measurement points, has not been possible to draw up in the present work.

Anyway, available data have allowed to point out that an unsuitable and acoustically incompatible location of important facilities can give rise to marked spatial variations in the city noise, with the existence of areas characterized by sound level distributions obeying to different statistics.

Since the most penalized areas cannot be easily redeveloped by the introduction of "facility pertinent zones" suitable to the urban characteristics of the specific areas, it is necessary to think of recovery plans.

We can affirm that, as the heavy traffic constitutes the main source of noise pollution, a desirable mitigation action would be that to find a new location for the landing-places far from residential areas to decongest the urban centre from the heavy traffic.

This action would give rise to the double benefit effect: to reduce the number of vehicles and to reduce the maximum noise levels being prohibited the noisiest vehicles.

\section{REFERENCES}

[1] Ouis D. (2001). Annoyance from road traffic noise: Review. Journal Environment Psychol 21: 101-20. https://doi.org/10.1006/jevp.2000.0187

[2] Chowdhury RB, Dey R, Alam MS, Chakraborty P. (2010). Extent of traffic induced noise in the noise sensitive institutions of Chittagong city, Bangladesh. Noise \& Vibration Worldwide 41(1): 28-36. 
https://doi.org/10.1260/0957-4565.41.1.28

[3] Langdon FJ. (1976). Noise nuisance caused by road traffic in residential areas: Part I and II. Journal Sound Vib 47: 243-82. https://doi.org/10.1016/0022$460 X(76) 90721-5$

[4] World Health Organization. (1999). In: Berglund B, Lindvall $\mathrm{T}$, Schwela $\mathrm{DH}$, editors. Guidelines for community noise. Geneva: WHO. http://www.who.int/iris/handle/10665/66217

[5] WG_HSEA. (2002). Position paper on dose-response relationships between transportation noise and annoyance, European Commission. Office for Official Publications of the European Communities, Luxemburg 2002- ISBN 92-894-3894-0.

[6] Brown AL, Lam KC. (1987). Urban noise surveys. Applied Acoustic 20: 23-9. https://doi.org/10.1016/0003-682X(87)90081-8

[7] Morillas JMB, Escobar VG, Sierra JAM, Gomez RV, Carmona JT. (2002). An environmental noise study in the city of Caceres, Spain. Applied Acoustic 63: 1061-70. https://doi.org/10.1016/S0003-682X(02)00030-0

[8] Schultz TJ. (1978). Synthesis of social surveys on noise annoyance. Journal of the Acoustical Society of America 64(2): 377-405. https://doi.org/10.1121/1.382013

[9] Astolfi A, Pellerey F. (2008). Subjective and objective assessment of acoustical and overall environmental quality in secondary school classrooms. Journal of the Acoustical Society of America 123(1): 163-73. https://doi.org/10.1121/1.2816563

[10] Don CG, Rees IG. (1985). Road traffic sound level distributions. Journal Sound Vibrations 100: 41-53. https://doi.org/10.1016/0022-460X(85)90341-4

[11] Tang SK, Chu SHK. (2001). Noise level distribution functions for outdoor applications. Journal Sound $\begin{array}{lll}\text { Vibrations } & 248(5): & 887,\end{array}$ https://doi.org/10.1006/jsvi.2001.3827

[12] International Organization for Standardization. ISO 1996/1-1982; ISO 1996/2, 3-1987.

[13] European Union. (2002). Directive 2002/49/EC relating to the Assessment and Management of Environmental Noise. Official Journal of the European Communities Number L189.

[14] Piccolo A, Plutino D, Cannistraro G. (2005). Evaluation and analysis of the environmental noise of Messina, Italy. Applied Acoustics 66(4): 447-465. https://doi.org/10.1016/j.apacoust.2004.07.005

[15] Burgess MA. (1977). Noise prediction for urban conditions related to measurement in Sydney metropolitan area. Applied Acoustics 10: 1-7. https://doi.org/10.1016/0003-682X(77)90002-0

[16] Cirianni F, Leonardi G. (2012). 2012 environmental modeling for traffic noise in urban areas. American Journal of Environmental Science 8(4): 345-351. https://doi.org/10.3844/ajessp.2012.345.351

[17] Filho JMA, Lenzi A, Zannin PHT. (2004). Effects of traffic composition on road noise: A case study. Transportation Research Part D, Transport and Environment 9: 75-80. https://doi.org/10.1016/j.trd.2003.08.001

[18] Griffiths I, Langdon FJ. (1968). Subjective response to road traffic noise. Journal of Sound and Vibration 8: 1632. https://doi.org/10.1016/0022-460X(68)90191-0

[19] Garcia A, Bernal D. (1985). The prediction of traffic noise levels in urban areas. Proceedings of the International Conference on Noise Control Engineering. Munich, Germany 843-846.

[20] Mofeed B, Imam R, Jamrah A. (2013). Noise mapping using GIS: A Case study from Amman. Journal of American Science 9(12): 646-652.

[21] Obaidat MT. (2008). Spatial mapping of traffic noise levels in urban areas. Journal of the Transportation Research Forum 47(2): 89-102. https://doi.org/10.5399/osu/jtrf.47.2.1711

[22] Salameh B, Imam R. (2014) Developing roadway traffic noise prediction models for the city of Amman. Journal of American Science 10(2s): 23-30. http://www.jofamericanscience.org

[23] Dursun S, Özdemir C, Karabörk H, Koçak S. (2006). Noise pollution and map of Konya city in Turkey. Journal of International Environmental Application and Science 1(1-2): 63-72. https://doi.org/10.1007/BF01240704

[24] Santos LC, Valado F. (2004). The municipal noise map as planning tool. Acústica, Guimarães, Portugal, Paper ID: 162

[25] Zannin PHT, Sant'Ana DQD. (2011). Noise mapping at different stages of a freeway redevelopment project $-\mathrm{A}$ case study in Brazil. Applied Acoustics 72: 479-486. https://doi.org/10.1016/j.apacoust.2010.09.014

[26] King EA, Rice HJ. (2009). The development of a practical framework for strategic noise mapping. Applied Acoustics 70 : $1116-1127$. https://doi.org/10.1016/j.apacoust.2009.01.005

[27] Wazir A. (2011). GIS based assessment of noise pollution in Guwahati City of Assam, India. International Journal of Environmental Sciences 2(2): 731-740. ISSN 0976-440.

[28] Abo-Qudais S, Abu-Qdais H. (2005). Perception and attitudes of individuals exposed to traffic noise in working places. Building and Environment 40(6): 778787. https://doi.org/10.1016/j.buildenv.2004.08.013 